\title{
O DISCURSO PEDAGÓGICO NO WHATSAPP E A CONSTITUIÇÃO DO ETHOS DISCURSIVO EM GRUPO DE GESTÃO ACADÊMICA
}

\author{
Uilson Nunes de CARVALHO Júnior (Unifesp)
}

\begin{abstract}
Nosso trabalho propôs analisar como a língua(gem) representa o discurso pedagógico institucionalizado em um grupo de gestão acadêmica no aplicativo WhatsApp de uma escola técnica estadual, atentando-se como o ethos discursivo é constituído e quais seus efeitos de sentido. Para tanto, utilizamos a Análise do Discurso de linha francesa, sobretudo os estudos de Maingueneau (1997, 2005, 2008, 2011, 2015), como também, observamos nessa ambiência os estudos das novas tecnologias da informação de Manuel Castells (2002) e Pierre Lévy (2000, 2003) valendo-se dos novos paradigmas de espaço-tempo da informação.
\end{abstract}

